\title{
Epigrafik Belgeler ve Antik Edebi Eserler Işı̆̆ında Magnesia ad Sipylum
}

\author{
Yasemin Sargin
}

Özet

Günümüzde Manisa İl sınırları içerisinde yer alan Magnesia ad Sipylum Kenti Sipylos (Spil/Manisa) Dağı'nın kuzey yamacı eteğinde kurulmuş bir Lydia Kenti'dir. Kent topografik olarak, Hermos (Gediz) Nehri'nin suladığı bereketli Gediz Ovası'na hakim bir durumdadır. Antik dönem yol güzergâhlarının bağlantı noktasında yer alan kent buna bağlı olarak ticari ve stratejik bir öneme de sahiptir. Smyrna'nın (İzmir) yaklaşık 32 km kuzeydoğusunda konumlanan Magnesia, bu komşu kentle iyi ilişkiler içerisinde olmuştur. Bu durum iki kent arasında gerçekleşen ve İÖ. 243 yılına tarihlenen sympoliteia anlaşmasını içeren epigrafik bir yazıt ile de belgelenmektedir.

Antik kentten bugüne az sayıda arkeolojik kalıntı ve epigrafik belge ulaşmıştır. Bunun dişında kent ile ilgili bilgiler antik yazarların aktardıklarından öğrenilmektedir. Bu çalışmada Magnesia ad Sipylum Kenti'ne dair bilinenler, epigrafik belgeler ve antik edebi eserlerin imkan verdiği ölçüde; tarihi-coğrafik ve sosyal-kültürel açılardan ortaya konulmaya çalışılmıştır.
Anahtar Kelimeler

Magnesia ad Sipylum

Manisa

Spil Dağı (Sipylos)

Eski Yunanca Yazıtlar

Makale Hakkında

Geliş Tarihi: 01.09.2020

Kabul Tarihi: 12.10 .2020

Doi: 10.18026/cbayarsos.789127

\section{Magnesia ad Sipylum in the light of Epigraphic Documents and Ancient Literary Works}

\begin{abstract}
Magnesia ad Sipylum is a Lydian City established on the northern foothills of Mount Sipylos (Spil/Manisa), within the borders of the modern Province of Manisa. Topographically, the city overlooks the fertile Gediz Plain irrigated by the Hermos (Gediz) River. Its location on the intersection of ancient itineraries gives the city commercial and strategic importance. Magnesia, located about 32 $\mathrm{km}$ northeast of Smyrna (Izmir), has had good relations with this neighboring city. This relation is also documented by an epigraphic inscription which contains the decree of sympoliteia between the two cities, dated to 243 BC.

A few archaeological remains and epigraphic documents have survived from the ancient city. Further the information of the city is acquired by the accounts of ancient writers. This study aims to present current information on Magnesia ad Sipylum in terms of historical-geography and socio-cultural aspects within the possibilities provided by epigraphic documents and ancient literary works.
\end{abstract}

Keywords

Magnesia ad Sipylum

Manisa

Mount Spil (Sipylos)

Ancient Greek Inscriptions

\section{About Article}

Received: 01.09.2020

Accepted: 12.10.2020

Doi: 10.18026/cbayarsos.789127

* Dr. Öğr. Üyesi, Manisa Celal Bayar Üniversitesi, Fen-Edebiyat Fakültesi, Arkeoloji Bölümü, ORCID ID: 0000-0002-4262-1943 (yasemin.sargin@cbu.edu.tr) 


\section{Araştırma Tarihi}

Magnesia ile doğrudan ilişkili bilimsel çalışmaların sayısı çok azdır. Kentin epigrafik araştırmalarını bir araya getiren ilk çalışma T. Ihnken'ın (1978) “Die Inschriften von Magnesia am Sipylos" adıyla yayımlanmış kitabıdır. Bunun dışında H. Malay'ın Manisa Müzesi'nde bulunan epigrafik yazıtları topladığı müze kataloğunda (Malay 1994) Magnesia ad Sipylum'a ait birkaç yazıtın ${ }^{1}$ bulunduğu bilinmektedir.

Kent tarihine ilişkin ilk çalışma O. Akşit (1983) tarafından kaleme alınan "Manisa Tarihi (Magnesia ad Sipylum) (Başlangıcından M.S. 395 Yılına Kadar)" isimli kitaptır. G. M. Cohen (1995), kentin Hellenistik Dönem yerleşimine ilişkin bilgileri kısa bir bölüm olarak “Magnesia ad Sipylum” başlığı altında yazmıştır. F. Daubner (2013), bir ansiklopedi maddesi altında "Magnesia ad Sipylum" adıyla kentin coğrafik ve tarihsel durumuna ilişkin birkaç paragraf ile bilgiler sunmuştur. Temel iki sözlük (RE ve DNP) çalışması da "Magnesia ad Sipylum" maddesi altında kent ile ilgili önemli bilgiler vermişlerdir².

Magnesia ad Sipylum'un bilimsel anlamda az araştırılmış bir yer olarak kalması yeni araştırmalar yapacak olan bilim insanlarının işini zorlaştırmaktadır. Bu bakımdan son yıllarda Magnesia ad Sipylum hakkında yapılan çalışmalar bir nebze de olsa artmıştır.

Bunlara örnek M. U. Doğan'ın yapmış olduğu çalışmalardır. Kendisinin kent ile ilgili ilk çalışması 2007 yılında tamamladığı "Magnesia Ad Sipylum: Arkeoloji, Topografya ve Tarihi Coğrafya İncelemesi" isimli Yüksek Lisans Tezi' dir. Buna ek olarak Doğan (2007b), "Manisa İl Merkezinde Keşfedilen Polygonal Duvarların Sipylos Magnesiası'nın Erken Dönemi ile İlişkisi"; 2008 yılında "Spil (Manisa) Dağı'nın Kuzey Yüzündeki Bir Grup Kaya Anıtı" ve "Sipylos Magnesiası Arkeolojisine Işık Tutan Yeni Bulunmuş Bir Kabartma" adıyla toplam üç makale daha yayımlamıştır.

Son yıllarda yapılmış bir başka çalışma kentten günümüze kalan Manisa Kalesi kalıntılarını Arkeoloji ve Sanat Tarihi yönünden değerlendiren ortak bir makale çalışmasıdır (Ermiş, Gündüz Küskü \& Y1lmaz 2016).

Çalışmamız bundan sonra yapılacak bilimsel araştırma ve projelere katkı sağlamayı hedeflemektedir. Daha önce kent üzerine Epigrafik ve Klasik Filoloji ağırlıklı Türkçe bir çalışmanın yapılmamış olması makalemizi özgün kılmaktadır.

\section{Kentin Tarihi Coğrafyası, Adı ve Mitolojik Hikayesi}

Antik Dönemde Sipylos (Spil) Dağı' nın eteğinde kurulmuş ve adı antik yazarlar tarafından bu dağ ismi ile birlikte anılan Magnesia ad Sipylum kenti Smyrna'nın (İzmir) yaklaşık $32 \mathrm{~km}$ kuzeydoğusunda yer almaktadır. Strabon, "Sipylos'un eteğinde Magnesia vardır" (13.3.5: $\eta$

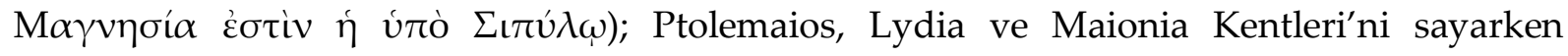

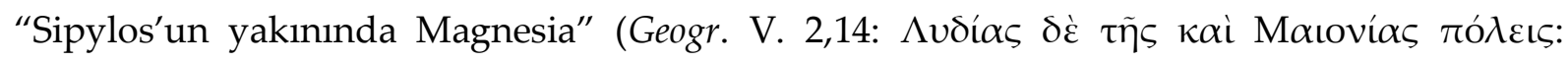

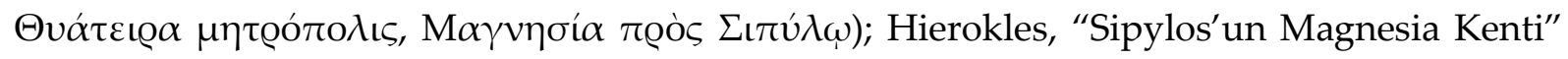

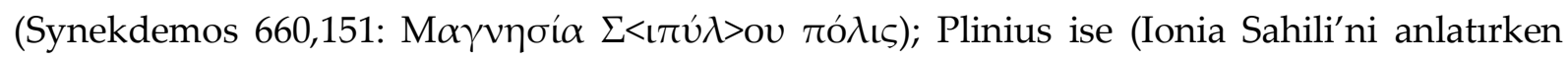
kıyıdan içeride kalan kenti "Sipylum" adıyla ifade edip burasının önceden Tantalis adıyla anıldığını ve Maionia'nın başkenti olduğunu aktarır (Nat. Hist. V 116/7: ...et Sipylum, quod ante Tantalis vocabatur, caput Maeoniae, ubi nunc est stagnum Sale). Ayrıca, Kioslu bir hâkimi

\footnotetext{
${ }^{1}$ Malay 1994, no. 218, 408, 512.

2 RE 14.1, 472-473, no. 3 ve DNP 7, 695, no. 3.
} 
onurlandıran yazıtta ise) Kent halkının adı, "Sipylos'un eteğinde oturan Magnesialılar" (I. v.

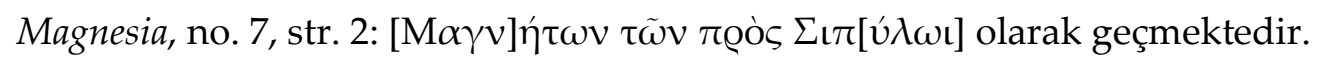

Magnesia ad Sipylum, Hermos (Gediz) Ovası'nın bereketli toprakları üzerinde bulunan Lydia $^{3}$ Bölgesi'nde kurulmuş önemli kentlerden birisidir. Konumu gereği yol güzergâhlarının bağlantı noktasındadır. Günümüzde Manisa İli sınırları içerisinde yer alan kent, zengin arkeolojik kalıntılara sahip değildir. Kentte henüz bir kazı çalışması ve sadece kent ve territoriumuna ilişkin spesifik bir yüzey araştırması yapılmamış olması bunun sebepleri arasındadır ${ }^{4}$ Bu yüzden makalemiz kent ile ilgili ileride yapılacak olan bilimsel çalışmalara da yön vermesi bakımından önem taşımaktadır.

Magnesia ad Sipylum'dan günümüze kadar ulaşmış “Akpınar Kaya Mezarı" ve "Pelops Tahtı" isimleriyle modern literatürde yer alan arkeolojik kalıntılar bilinmektedir ${ }^{5}$. Bunların dışında M. U. Doğan, Magnesia ile ilgili yazmış olduğu Yüksek Lisans tez çalışmasını yaparken kentin arkeolojik ve tarihsel coğrafyasına yönelik bir yüzey araştırması yapma ihtiyacı duymuştur. Ekibiyle birlikte yaptıkları küçük çaplı bu araştırma sonucunda yeni bir kabartma tespit etmişlerdir (Doğan 2007b).

Günümüzde "Manisa Kalesi" olarak adlandırılan ve Magnesia ad Sipylum Kenti'nin güneyinde iç kale ve dış kale olmak üzere ikiye ayrılmış Geç Bizans Dönemi'ne tarihlenen sur duvarları bulunmaktadır. İç surlar "Sandık Kale" adıyla bilinen mevkide beşgen planlı yapılmıştır ve kentin kurulduğu dağın zirvesinde yer almaktadır. Dış kaleye ait duvarlar ise kentin daha alt seviyesinde Sipylos Dağı'na paralel şekilde uzanmaktadırlar (Ermiş, Gündüz Küskü \& Y1lmaz 2016, 247 ve 249).

Kent territoriumuna ait Ormoitenoi/Ormoita katoikiası, Magnesia ad Sipylum'un kuzeydoğusunda bulunan günümüzde Karaağaçlı Mahallesi olarak adlandırılan kasabadan ele geçen iki yazıtta belgelenmektedir ${ }^{6}$.

Antik Dönem'de Hermos (Gediz) Irmağı'nın suladığı verimli ova üzüm bağları ve şarap üretimi ile ünlüdür. Üzüm dışında çeşitli tarım ürünleri ve tekstil ihracatının yapılması bölgenin ekonomik zenginliğine katkı sağlamaktadır. Ayrıca Sardeis'in içinden geçen Paktolos (Sart) Çayı'nın "altın taşıyan ırmak" unvanı ile anılması Sardeis'in ve özellikle Lydia'nın zenginliğine zenginlik katmıştır (Malay 1983, 51-52, 54-60; Tanrıver 2006, 178).

\footnotetext{
3 Antik Dönemde Lydia Bölgesi'nin batısında Ionia ve Aiolis; doğusunda Phrygia bulunmaktadır. Kuzeyde Mysia ile sınırın Kaikos (Bakırçay); güneyde Karia ile olan sınırını ise Maiandros (Büyük Menderes) Irmağı belirlemektedir. Bkz. RE s. v. Lydia; Umar 2001; Greenewalt 2010, 7; Sargın 2019, 2526. Günümüzde Batı Anadolu'nun ortasında yer alan Manisa'nın tamamını, Uşak ilinin büyük bir bölümünü kapsamaktadır.

${ }^{4}$ Kentte kapsamlı bir şekilde herhangi bir kazı çalışması ya da yüzey araştırması yürütülmemiştir. 1984 - 1988 yılları arasında R. Meriç (Meriç 1986-1990) tarafından İzmir ve Manisa illerinde arkeolojik yüzey araştırması yapılmıştır. Bunun dışında Malay (1984) tarafından "Manisa ve Denizli İllerinde Epigrafi Araştırması" yapılmıştır. Bununla birlikte Manisa Celal Bayar Üniversitesi, Fen-Edebiyat Fakültesi, Arkeoloji Bölümü, Dr. Öğretim Üyesi Volkan Yıldız tarafından "Magnesia ad Sipylum Kenti ve Çevresi" isimli yüzey araştırma projesi Kültür Bakanlığına sunulmuştur ve Bakanlık araştırmayı onaylamıştır.

${ }^{5}$ Söz konusu arkeolojik kalıntılara ilişkin daha ayrıntılı bilgiler için bkz. Doğan 2008a, 69-75.

${ }^{6}$ Ormoitenoi/Ormoita katoikiasına ilişkin bkz. Şahin 1998, 116.
} 
Kentin mitolojik hikayesinde Yunanlıların Anadolu'ya yerleşmesinden önce Sipylos Dağı ve çevresinin Tantalos adında bir krala ait olduğu anlatılır. Efsaneye göre kendisi Zeus ile Pluton'un oğlu olmalıdır. Kızının Niobe, oğlunun ise Pelops ${ }^{7}$ olduğu düşünülmektedir. Tanrılar ile yakın ilişki içinde olan Tantalos bir gün onları ziyafete davet eder ve Tantalos, tanrıların önüne yemek olarak oğlu Pelops'u doğrayıp koyar. Tanrılar arasından bir tek Demeter bunu fark etmez ve Pelops'un bir omzunu yer. Ancak diğer tanrılar bu durumu anlar ve Zeus, Pelops'u yeniden canlandırır. Tanrıları böyle bir oyunla kandırmak isteyen Tantalos ise bu ya da başka bir sebepten dolayı Hades'e gönderilir. Tantalos'un işkencesi olarak geçen bu cezayı Homeros (Odyss. XI, 582 vd.), “...sürekli susaması ve bir gölün içinde olmasına rağmen eğilip su içmek istediği zaman suyun geri çekilmesi ve etrafı meyve ağaçlarıyla dolu olmasına rağmen uzanıp koparmak istediği zaman bir rüzgarın meyveleri alıp uzağa savurması" ifadeleriyle anlatmaktadır (Erhat 1989, 304-305; Bean 1997, 36-37). Tantalos'un kızı olduğu düşünülen Niobe'nin Magnesia ad Sipylum ile olan ilişkisi ise şöyledir: Altı erkek ve altı kız çocuğu olan Niobe, birer erkek ve kız evlat sahibi Leto'yu küçümser. Bunun üzerine annelerinin intikamını almak isteyen Apollon ve Artemis oklarıyla Niobe'nin on iki evladını öldürür. Niobe bu acıya dayanamayıp Sipylos Dağı'na gelir ve orada taşa dönüşür (Erhat 1989, 237-238). Zira H. T. Bossert (1942) tarafından, kentin hemen yakınında, Sipylos Dağı'nın güneybatısında uzaktan görünümü oturan ve ağlayan bir kadına benzetilen bir kaya bulunmuştur. Bossert, bu kayanın Niobe olabileceğini önermektedir (Karş. Bean 1997, 34). Ayrıca Pausanias, Niobe hakkında, Sipylos Dağı'na çıkıp bahsi edilen kayaya yakından bakıldığı zaman sadece kayalıktan ibaret olduğunu ancak uzaklaşınca bu kayanın başı eğik bir kadına benzediğini aktarmaktadır (Karş. Akurgal 1989, 383-384). Günümüzde ise bu hikaye halk arasında "Ağlayan Kaya" adıyla hâla anlatılır ve kayanın bulunduğu yer "Ağlayan Kaya Mevkii" olarak geçer.

\section{Kentin Tarihsel Gelişimi}

Magnesia ad Sipylum'un en erken tarihine ilişkin bilinenler oldukça azdır. İÖ. 4. yüzyıl ortasından önceye ait tek kaynak Lesboslu Hellanikos'un kent hakkında yazdıklarıdır (FGrH 4 F 191). Kent, Lydia Krallı̆̆1 Dönemi'nde önemli kentlerden birisidir. Persler İÖ. 547/6 yılında Sardeis'e sardırmışlardır. Pers Kralı Kyros ile son kral Kroisos arasında yaşanan savaşta Persler Sardeis'i yakıp yıktıktan sonra Kroisos'u esir almışlardır. Hükümranlığı son bulan Lydia Krallığı'nın toprakları böylelikle Pers hâkimiyetine geçmiştir ve Sardeis satraplık merkezi olmuştur (Herodotos, I.114). Hellenistik Dönem'e gelindiğinde Makedonia Kralı Büyük İskender, Doğu Seferi için uzun bir yolculuğa çıkmış ve çıtığı bu seferde Küçük Asya' da pek çok kenti ve bunların territoriumunu kendi egemenliği altına almıştır. Bunlardan biri de Pers yönetimi altında olan Lydia topraklarıdır. Pers boyunduruğundan kurtulan Lydia bu sefer Büyük İskender'in emri altına girmiştir. İskender'in ölümünün ardından

\footnotetext{
${ }^{7}$ Pelops'un mitolojik hikayesi hakkında daha ayrıntılı bilgi için bkz. Erhat 1989, 262.
} 
krallığının toprakları ardılları arasında paylaşılmıştır. Thrakia ve Batı Anadolu toprakları İskender ardıllarından Lysimakhos'a kalmıştır.

Lysimakhos ile onun eski müttefiği Seleukos I arasında Magnesia ad Sipylum'un kuzeyinde Hyrkanis düzlüklerinde Kourupedion Savaşı (İÖ. 281) meydana gelmiştir. Savaşta büyük bir yenilgiye uğratılan Lysimakhos öldürülmüştür. Lydia toprakları ve dolayısıyla Magnesia Kenti Seleukoslar'ın egemenliği altına girmiştir.

İÖ. 243 yılına tarihlenen, Magnesia ad Sipylum ile Smyrna arasında imzalanan sympoliteia anlaşması ile ilgili bilgileri içeren bir yazıttan Seleukos krallarının askerlerini Magnesia ad Sipylum'a yerleştirdikleri ve burayı güçlü bir kale olarak kullandıkları öğrenilmektedir. Söz konusu yazıtta askerlerin bir katoikia olarak organize edildiği anlaşılmaktadır. G. M. Cohen (1995, 216), katoikianın askeri bir organizasyon olduğunu ve iki tagma'ya (askeri birlik) bölündüklerini ve her bir askeri birliğin kendi grammateusi olduğunu belirtmektedir. Böylece, Smyrna ile yapılan bu görüşmelerden yola çıkarak bu askerlerden oluşan katoikianın baskın bir yapısı olduğu anlaşılabilmektedir. Yapılan anlaşmanın içeriğine göre Smyrnalılar bütün Magnesialılar'a vatandaşlık hakkı bahşetmişlerdir. İÖ. 216/213 yılında Magnesia ad Sipylum, Seleukos Kralı Antiokhos III Megas'ın hâkimiyeti altındadır. İÖ. 190/189 yılında Antiokhos III ile Roma arasında Magnesia Savaşı (İÖ. 190/189) meydana gelmiştir (Liv. XXXVI 43 ve XXXVII 37; Appian., Syr. 30). Roma consul'ü L. Cornelius Scipio Asiagenus komutanlığında yürütülen savaşta Antiokhos III yenilmiştir (Grainger 2002). Savaşın sonucunda Magnesia toprakları Romalılar tarafından Pergamon Kralı I. Eumenes'e bir nevi hediye olarak bırakılmıştır (Liv. XXXVI 56, 2-5). Kentin bu durumu İÖ. 133 yılında Pergamon Krallı̆̆ı'na ait bütün toprakların miras yoluyla Roma'ya bağışlanmasıyla son bulmuştur. Bunun akabinde Magnesia ad Sipylum dahil tüm Batı Anadolu Kentleri “Asia Eyaleti”(İÖ. 133/129) adıyla organize edilen eyalete dahil edilerek Roma kontrolü altına geçmiştir.

$\mathrm{Bu}$ tarihten sonra Magnesia ad Sipylum, Roma Devleti'nin yanında olduğunu Roma ve Pontos Kralı Mithradates VI Eupator arasında gerçekleşen I. Mithradates Savaşı'nda8 (ïÖ. 8985) göstermiştir. Öyle ki, Magnesia ad Sipylum'a savaşın sonunda galip gelen Roma generali Sulla tarafından civitas libera (özgür kent) imtiyazı bahşedilmiştir (Liv. LXXXI; Paus. I 20, 3-5; Plut. prae. ger. rei publ. 14, 8-9; Appian. Mithr. 21, 61; Strab. 12.3.5). Bunun dişında Magnesia ad Sipylum, Plinius'un (Nat. Hist. V 120) aktardığına göre, Asia Eyaleti'nde Smyrna conventus'una (mahkeme) bağlı bir kent idi. Küçük Asya'daki diğer kentlerin yaşadığı gibi Magnesia ad Sipylum'un da İS. 17 yılında yaşanan depremde oldukça büyük zarar gördüğü ve İmparator Tiberius tarafından yeniden yapılanma yardımı aldığı Tacitus (ann. II 47) ve Strabon'un (12.8.18 ve 13.3.5) aktarımlarından öğrenilmektedir. Puteoli'de ele geçen bir yazittan (CIL X 1624; ILS, 156 = I. v. Magnesia, T25; I. v. Kyme, T152 ve s. 222) Batı Anadolu'da depremden zarar görmüş kentlerin bir araya gelip İmparator Tiberius'a Roma'da Venüs Tapınağı'nda bir heykel yaptırarak ithaf ettikleri öğrenilmektedir. Heykel kaidesinin yazıtında imparatorun yardım ettiği diğer kentlerle birlikte Magnesia Kenti'nin adı da

\footnotetext{
${ }^{8}$ Roma ve Pontos Kralı Mithradates VI Eupator arasında yapılan savaşlara ilişkin daha ayrıntılı bilgi için bkz. Arslan 2007.
} 
bulunmaktadır9. Hieronymos (Khronik 172), söz konusu depremde sarsılan ve zarar ve gören on iki kent arasında Magnesia'yı da saymaktadır.

\section{Kentin İdari Yapısı}

Ele geçen epigrafik belgelerin sayısı az olmasına rağmen, yine de kentin idari sistemine ilişkin bazı bilgilere ulaşılabilmektedir.

T. Ihnken (1978) tarafından İÖ. 243 yılına tarihlendirilen, Magnesia ad Sipylum ile Smyrna arasında gerçekleşen anlaşmayı içeren kararname (decretum) kentten ele geçen en erken tarihli epigrafik belgedir (I. v. Magnesia, no. 1; I. Smyrna II.1, no. 573). Söz konusu bu decretum üç bölümden oluşmaktadır. Birinci bölüm; Smyrna ile Magnesia ad Sipylum arasındaki anlaşma ile ilgili karar (str. 1-34), ikinci bölüm; iki kent arasındaki anlaşma metni (str. 34-89), üçüncü bölüm ise Palaimagnesia ile ilgili Smyrnalılar'ın kararından (str. 89-108) meydana gelmektedir. Yazıtın birinci bölümünün ilk satırı "komutanlardan oluşan strategos heyetinin dilekçe/öneri vermesi üzerine $(\sigma \tau \varrho \alpha \tau \eta \gamma \tilde{\omega} \nu \gamma \nu \omega \dot{\mu} \eta)^{10}$, demos (halk meclisi) karar verdi" ifadesiyle başlamaktadır. Söz konusu yazıttan, kentin idari siteminde önemli karar mercii olan demosun karar yetkisini strategoslar ile birlikte elinde bulundurduğu anlaşılmaktadır ${ }^{11}$.

Kentten ele geçen bir başka yazıtta, kent yönetiminde önemli bir yere sahip olan demos kurumu bu kez Asia Eyaleti proconsulü (vali) Potitus Messala'y1 ${ }^{12}$ (PIR ${ }^{1}$ V, no. 94) kentin kuruluşundan beri patron ve euergetesi (hayırsever) olarak onurlandırmaktadır (le Bas Waddington 1972, 1660a; OGIS 460; IGRR IV, 1338; I. v. Magnesia, no. 2). Demos kelimesinin tamamlama olarak geçtiği diğer bir onurlandırma yazıtında ise (IGRR IV, 1346; TAM V.2 1365; I. v. Magnesia, no. 3) Marcus oğlu L. Antonius'un adı kentin euergetesi ve tamiası (quaestor = haznedar) olarak geçmektedir. Antik Dönemde halk yararına faydalı işler yapmış,

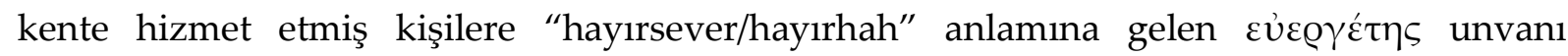
verilmiştir. Magnesia'da ele geçen yazıtlardan söz konusu kişilerin nasıl bir hayırseverlik yaptıkları tespit edilememektedir. Ancak bu unvan ile onurlandırıldıklarına göre Magnesia Kenti ve Halkı için faydalı işler yapmış oldukları anlaşılmaktadır. Ayrıca bu kişilerden Potitus Messala'nın merkezi yönetimin en üst düzey yöneticiliğini (vali); diğeri L. Antonius'un ise kent memuriyetleri arasında önemli bir yeri olan tamiaslık görevini icra etmesi dikkat çekmektedir. İlaveten kentte iki tamias memurunun daha var olduğu

\footnotetext{
9 Puteoli'den ele geçen kaidede toplam 14 kentin tasviri ve tasvirlerin altında kentlerin adı bulunmaktadır. Konuya ilişkin daha ayrıntılı bilgi için bkz. Weisser 2008, 112-117.

${ }^{10}$ Strategoslar Hellenistik Dönem'den itibaren kentlerde komutan olmanın dışında boule' de idari olarak son derece öenmli rolller üstlenmişlerdir. Çağ 2018, 10-23 ve 44-46.

11 Küçük Asya'da strategos memurunun Klasik, Hellenistik ve Roma İmpartorluk Dönemi'nde üstlendiği görevleri, yerine getirdiği yükümlülükleri, çeşitleri ve görev süreleri üzerine bkz. Çağ 2017, 281-292; 2018, 4-84.

12 Potitus Valerius Messala, İS. 5 yılı consulü ve İS. 11/12 yılında Asia Eyaleti valisidir. Messala, Magnesia ad Sipylum hariç Didyma'da da patron ve euergetes (OGIS II 494) olarak onurlandırılmıştır. Babası Potitus Valerius Messalla, İÖ. 32 ya 29 yılı consul suffectusu seçilmiştir ve o da oğlu gibi Asia Eyaleti proconsullüğü yapmıştır. Karş. Magie 1950, 1347, no. 60; Eilers 1999, 77-80.
} 
bilinmektedir. Bunlar Smyrnalılar' in derneğ ${ }^{13}$ ile ilgili yazıtta belgelenen ve derneğin tamias görevlileri olan Caius Marius Poplius ve T. At. Eutykhianos'tur (I. v. Magnesia, no. 18).

Diğer taraftan, Diognetos oğlu Aleksandros'un kendisi ve bizzat torunları için yaptırdığ 1 mezarı üzerinde bulunan yazıtın (CIG 3410; IGRR IV,1339; I. v. Magnesia, no. 19; TAM V.2 1372) proconsul Statius Quadratus' un ${ }^{14}$ görevi sırasında yazılmış olduğu öğrenilmektedir.

Kentten ele geçen bir başka onurlandırma yazıtında demos haricinde kentin idari sistemine ilişkin diğer önemli kurumlarının adının geçtiği de görülmektedir. İÖ. 2. yüzyıla tarihlenen bu yazıta göre demos ve boule (danışma meclisi), strategosların önerisiyle ${ }^{15}$ ( $\gamma v \omega ́ \mu \eta$

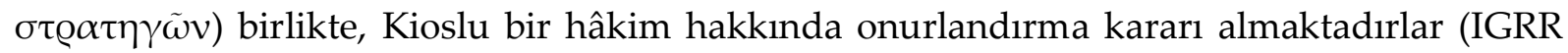
IV, 1344; TAM V.2 1368; I. v. Magnesia, no. 7).

Roma İmpatorluk Dönemi'nde Magnesia ad Sipylum Kenti'nin tek başına polis statüsüyle ya da demos kurumu ile Roma imparatorlarını onurlandırdıkları görülmektedir. Ele geçen yazıtların tarihi İmparator Traianus (98-117) ile başlamakta ve büyük ihtimalle Septimius Severus (193-211) ile son bulmaktadır. Söz konusu yazıtlardan ilkinde demos, imparator Traianus'u arkhon Quintus Iounius Marcellinus'un heykelin dikim işiyle ilgilenmesi üzerine onurlandırmaktadır (TAM V.2 1360; IGRR IV, 1333; I. v. Magnesia, no. 8). İmparator onurlandırmalarına ikinci örnek Hadrianus'un (117-138) onurlandırma yazıtıdır (I. $v$. Magnesia, no. 9). Söz konusu yazıttan kent yönetim organlarından hangisinin imparatoru onurlandırdığı öğrenilememektedir. İmparator onurlandırmalarına ilişkin bir diğer üç yazıt ise Septimius Severus'a aittir. Bu yazıtlardan ilki İS. 193-211 yıllarına tarihlenmektedir. Yazıtta Magnesia ad Sipylum "polis" statüsüyle Septimius Severus'u, masrafları Valentianus'un kendi cebinden ödemesi üzerine onurlandırmaktadır (IGRR IV, 1335; I. v. Magnesia, no. 10; TAM V.2 1361). Heykelin dikim işiyle ise Karikos oğlu protos arkhon Hermogenes ilgilenmiştir. Yazıttan anlaşıldığı üzere (Keil - Premerstein 1908, no. 4; AE 1909, 179; IGRR IV 1336; I. v. Magnesia, no. 11; TAM V.2 1362) polisin tek başına onurlandırdığ Septimius Severus'un heykelinin dikim işiyle protos strategos ${ }^{16} \mathrm{Ti}$. Cl. Iolaos Restitutus ilgilenmiştir ve bu onurlandırma synarkhonların ortak yönetimleri sırasında gerçekleşmiştir. Bir diğer onurlandırma yazıtında ise demos, Crispus Optatus'un protos arkhon'luğu sirasında yine imparator Septimius Severus'u heykelini dikerek onurlandırmıştır (IGRR IV, 1337; I. v. Magnesia, no. 12; TAM V.2 1363). Başka bir yazıttan isimleri tam olarak öğrenilemeyen iki imparatora ithaf da bulunulduğu anlaşılmaktadır ${ }^{17}$ (CIG 3406; I. v. Magnesia, no. 14). Yukarıda bahsettiğimiz imparator onurlandırmalarının belgelendiği yazıtlardan anlaşıldığ

\footnotetext{
${ }^{13}$ Smyrnalılar'ın derneğine ilişkin bilgi için bkz. aş. s. v. "Kentteki Sosyal Yaşam” ve ayrıca dn. 25.

${ }_{14}$ Statius oğlu, ordo senatorius mensubu olan Statius Quadratus 142 yılında consul ve 156/7 y1lında Asya Eyaleti'nde proconsul olarak görev yapmıştır. Bkz. PIR ${ }^{1}$ S, no. 640; RE III A, 2221-3, no. 21; DNP 11, 929. ${ }^{15}$ Konuya ilişkin bkz. yuk. dn. 10 ve 11.

16 İs. 2. yüzyılda, komutanların oluşturduğu heyete (strategoi) protos strategos "birinci strategos" başkanlık etmiştir. Konuya ilişkin ayrıntılı bilgi için bkz. Çağ 2018, 97-99.

${ }_{17} \mathrm{Bu}$ imparatorlar muhtemelen Marcus Aurelius ve Lucius Verus (İS. 161-169) olabilir. Krş. I. v. Magnesia, 138, no. 14.
} 
üzere heykelin dikim işiyle genel olarak kentin protos arkhon, protos strategos ve synarkhon gibi en üst düzey yöneticilerinin ilgilendiği görülmektedir.

Kentten bilinen bir diğer kurum gerousia (yaşlılar) meclisidir. Anonymus bir mezar yazıtında (I. v. Magnesia, no. 23; TAM V.2 1386) gerousia meclisine para ödemesi yapılmasına ilişkin bir ifadenin geçtiği görülmektedir. Ancak bu paranın miktarı ve ne için ödeneceği yazıttan tam olarak öğrenilememektedir.

Kent yönetimine ilişkin ve ele geçen epigrafik belgeler aracılı̆̆ıyla belgelenen diğer memurlar ise stephanephoros, gymnasiarkhos, tamias, logistes ve synarkhondur.

Kentten ele geçen yazıtlardan bilinen ve yukarı sözü edilen memuriyetlerden biri stephanephoriadır ${ }^{18}$. İS. yaklaşık 150 yılına tarihlenen bir mezar yazıtında (IGRR IV, 1342; I. v. Magnesia, no. 20; TAM V.2 1345) Publius Aelius [falanca] adında birisinin stephanephoria memuriyetinin devamlılı̆̆ için para ödediği anlaşılmaktadır. Öyle ki Publius Aelius [---], kendisi ve oğullarının stephanephorosluğu ve bu memuriyetin ebedi olması için 10.000 denaria ödeyerek memuriyeti satın almıştır (Gökalp-Özdil 2018, 201-202). Böyle bir bağışta bulunarak stephanephoria için bir vakıf kurulumu gerçekleşmiştir (Laum 1914, 90, no. 80).

Stephanephoria ile ilgili bir başka yazıta göre olimpiyatlardaki güreş müsabakalarında zafer kazanmış olan Hermagoras soyunu (bkz. aş. s. v. “Kentteki Sosyal Yaşam) stephanephorosların torunu olmasına dayandırmakta ve böyle bir soydan gelmesiyle övünmektedir. Anlaşılan kendisi bu görevi üstlenmemiş olmasına rağmen ataları arasında bu görevi yapanlar ile anılmayı prestij unsuru olarak görmüştür.

Kentten bilinen bir diğer önemli görev ise gymnasiarkhiadır. Demos, Dikaphenes oğlu stephanephoros ve gymnasiarkhes Dikaphenes'i gençlere, yaşlılara, çocuklara ve palaestrada eğitim almamış olanlara ünsever bir şekilde büyük bir küp yağ verdiği için onurlandırmaktadır (Robert - Robert 1948, 127-131, no. 50; I. v. Magnesia, no. 34). Söz konusu yazıttan Dikaphenes'in, stephanephoria ve gymnasiarkhia gibi önemli ve pahalı görevleri üstlenmiş olduğu anlaşılmaktadır.

Magnesia ad Sipylum territoriumu içerisinde yer alan Ormoitenoi katoikiası, logistes Tiberius Claudius Kleitianos'u son derece iyi ve erdemli bir adam, hem kendi memleketinde önde gelen hem de eyalette göze çarpan biri olması ve halka karşı gösterdiği iyi niyeti sebebiyle onurlandırmaktadır (IGRR IV, 1343; I. v. Magnesia, no. 32). Bu yazıtta dikkati çeken bir diğer unsur Kleitianos'un logisteslik memuriyetini üstlenmiş olmasıdır19. Roma İmparatorluk Dönemi idari sisteminde İS. 2. yüzyılda varlığını gösteren bu memuriyet Küçük Asya

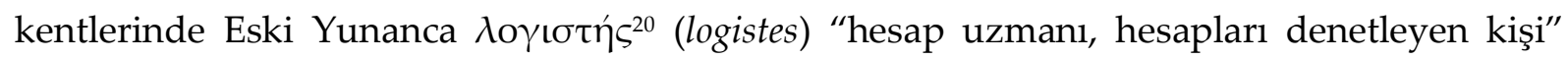

\footnotetext{
18 Stephanephoria çelenk taşıma anlamına gelen ve Küçük Asya'da Hellenistik ve Erken Dönem'de dini bir memuriyet iken Roma İmpartorluk Dönemi'nde ise dini olmaktan ziyade kent cursusunda önemli bir yere sahip olan bir memuriyet haline gelmiştir. Stephanephoria görevi ve stephanephoros memuru hakkında daha ayrıntılı bilgi için bkz. Gökalp-Özdil 2018, 197-203.

19 Söz konusu yazıtın yorumlarına ilişkin bkz. Sargın 2017, 88, 178, T1-34.

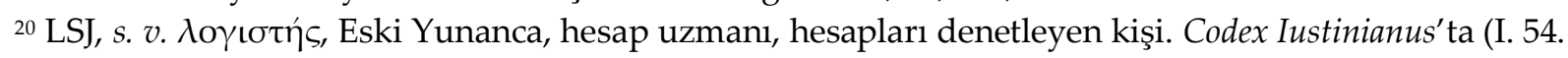

3), curator rei publicae, qui Graeco vocobulo logista nuncupatur: "Curator rei publicae, Yunan kelime bilgisinde logista" olarak geçmektedir.
} 
anlamında kullanılmaktadır ${ }^{21}$. Söz konusu yazıttan kentin ya da katoikianın nasıl bir mali sıkıntı yaşadığı öğrenilememektedir. Bununla birlikte logistesin hangi yolu izleyip sorunu çözüp çözmediği ise yine anlaşılamamaktadır.

\section{Kentteki Sosyal Yaşam}

Magnesia ad Sipylum Kenti'nden bazı ünlü kişilerin varlığ bilinmektedir. Bunlar arasında Suda (İS. 10. yüzyıl), epik şair Simonides'in Sipylos'un Magnesia Kenti'nden olduğunu söylemektedir. Halikarnasoslu Dionysios (De compositione verborum 4), Magnesia ad Sipylumlu rhetor Hegesias'tan ${ }^{22}$ (ayrica bkz. FGrH 142, T 4; DNP 5, 1998, s. 236-237, no. 2) bahsetmektedir. Cicero Magnesia ad Sipylumlu rhetor Dionysios'tan (ayrica bkz. RE V, 975, no. 125) ders aldığından ve onun öğrencisi olduğundan kendi metinlerinde (Brutus 316) söz etmektedir. Plutarkhos da (Cic. 4), Magnesialı Dionysios'tan bahsetmiştir.

Kentten ele geçen yazıtlardan bir sporcunun adı öğrenilmektedir. Yazıtta kendisini stephanephorosların soyundan gelen bir güreşçi olarak tanıtan Hermagoras'ın Magnesia ad Sipylum haricinde Atina, Smyrna ve Tarsos vatandaşlı̆̆ının olduğu da ifade edilmektedir (IGRR IV, 1344; I. v. Magnesia, no. 6; TAM V.2 1368; Çokbankir 2010, 194-195, no. 141). Söz konusu yazıtta Hermagoras, 229. Olympia (İS. 137 yılı) yarışmasında Pisa' da gerçekleştirilen Büyük Olympia Bayramı'nda yapılan güreş müsabakasında zafer kazandığı ve Magnesialılar arasında eskiden beri birinci ve tek kişi olduğu için onurlandırılmıştır. Ayrıca Hermagoras; Panathenaia Bayramı'nda, Sebasta'da çocuklar ve sakalı henüz bitmiş delikanlılar arasında olan güreş yarışmasında Pergamon'da, Ephesos'taki Asya Birliği Oyunlarında ve son olarak Nikomedeia'da yapılan müsabakalarda zafer kazanmıştır.

Kentten adı bilinen bir diğer sporcu yine güreş müsabakalarında zafer kazanmış Marcus Aurelius Hermagoras'tır. Napoli'de ele geçen bir yazıtta ${ }^{23}$ Marcus Aurelius Hermagoras'in memleketi sadece Magnesia ad Sipylum olarak ifade edilmiştir. T. Ihnken (I. v. Magnesia, 167), bu M. Aur. Hermagoras ile bir önceki sözü edilen Hermagoras'ın akraba olduğunu düşünmektedir.

Bir diğer güreşçi Ephesos'tan ele geçen bir yazıttan (I. v. Ephesos III, no. 700; I. v. Magnesia, T34) adı öğrenilen Dionysios'tur.

Tralleis kentinden ele geçen bir yazıtta (CIG 2933; le Bas - Waddigton, 605; OGIS, 501; I. v. Tralleis - Nysa I, 50; I. v. Magnesia, T32; Sargın 2017, T1-11b) Serapion oğlu, Magnesia ad

\footnotetext{
${ }^{21}$ Latince terminolojide curator rei publicae ya da bazen curator civitatis denilen bu görevli Roma İmparatorluk Dönemi’nde imparator tarafından görevlendirilerek eyalet kentlerinin kamu hesaplarını denetlemiş, onları mali yönden kontrol ederek ekonomik sıkıntıdan kurtarmaya çalışmıştır. Söz konusu üst düzey yöneticilik düzeyindeki curatio rei publicae/logisteia memuriyeti 2017 yllında "Roma İmparatorluk Dönemi Kü̧̈ük Asya'sında curatores rei publicae" başlığ 1 ile tarafımdan Doktora Tezi olarak tamamlanmıştır. Konuya ilişkin daha ayrıntılı bilgi için bkz. Sargın 2017, 1 ve 15.

22 Strabon (12.1.41), Magnesia ad Maendrum'u (Menderes kıyısındaki Magnesia) anlatırken rhetor Hegesias'tan bahsetmektedir. Ancak büyük ihtimalle bu kişi Magnesia ad Sipylumlu Hegesias olmalıdır. Yani Strabon Magnesia kentlerini karıştırmış olmalıdır.

${ }^{23}$ IG XIV 739; IGRR IV 444; I. v. Magnesia, no. T33.
} 
Sipylumlu Serapion'un adı öğrenilmektedir. Söz konusu yazıtta Serapion olympionikes unvanı ile anılmaktadır ${ }^{24}$.

Kentten ele geçen bir adak yazıtında (CIG 3408; I. v. Magnesia, no. 18; TAM V.2 1346)

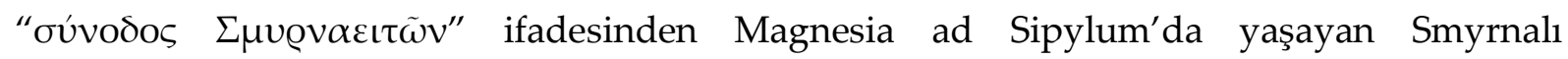
vatandaşların bir dernek kurmuş oldukları anlaşılmaktadır ${ }^{25}$. Kentte sosyal bir derneğin varlığı kentin kültürel bir zenginliğe sahip olduğunu göstermektedir.

Magnesia ad Sipylum kentinin günlük sosyal yaşamını daha iyi anlayabilmek için kentten ele geçen mezar yazıtlarına biraz daha ayrıntılı bakmak gereklidir. Örneğin çömlekçi Menophilos ve eşi Ammion tek oğulları olan Menophilos'un anısına bir mezar yaptırdıklarını belirtmektedirler (I. v. Magnesia, no. 29; TAM V.2 1381).

Bir başka kararname yazıtından (TAM V.2 1342; I. v. Magnesia, no. 7) adı öğrenilemeyen Kioslu (Gemlik) bir hâkimin Magnesia halkı için ağır olan vergi yüklerinin daha hafif olmasına karar verdiği belgelenmektedir. Magnesialılar hâkimin verdiği bu kararın kendileri yararına olduğunu düşünmüş olmalılar ki boule ve demos hâkimi onurlandırarak yüceltmişlerdir. Adrastos oğlu Adrastos'un Rhodoslu olduğu kendisine ait mezar yazıtından öğrenilmektedir (REG 13, 1900, s. 498, no.1; I. v. Magnesia, no. 30; TAM V.2, 1370). Ayrica kentten bilinen bir heykel kaidesinde heykeli "Pergamonlu Aias oğlu Menas'ın yaptırdığı" ifade edilmiştir (I. v. Magnesia, no. 35; TAM V.2 1358). Magnesia ad Sipylum Kenti'nde Pergamon'dan gelen bir heykeltraşın²6 olması kentte heykeltraşlık üzerine faaliyetlerin olduğu sonucuna işaret edebilir ${ }^{27}$.

Diognetos oğlu Aleksandros'un mezar yazıtında (CIG 3410; IGRR IV, 1339; I. v. Magnesia, no. 19; TAM V.2 1372) bu mezarı kendisi ve kendi soyundan gelenler için yaptırmış olduğu, başka hiç kimsenin buraya gömülmeye izinli olmadığı yazılıdır. Eğer bir kimse buna

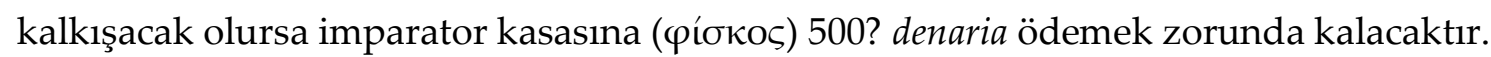

Kentten bilinen bir diğer yazıtta Aleksandros Gemnis'in, mezarı ve ölü külü konulan kabı kendisine ve hayat arkadaşı Meltine'ye yaptırdığı belgelenmektedir (I. v. Magnesia, no. 28; TAM V.2 1371). Söz konusu yazıt Gemnis ve eşinden başka hiç kimsenin buraya gömülmeye izinli olmadığını ve eğer onlardan başka birisi konulacak olursa kent kasasına 1500 denaria ödemek zorunda olduğunu açıklayan bir ceza formülü ile bitmektedir.

\footnotetext{
${ }^{24}$ Tralleis'ten ele geçen söz konusu yazıtta “Ionia ve Hellespontos'un sanatçllar derneği (Dionysos tekhnitai), ordo syncleticus mensubu ve Romalılar'ın strategos'u Iulius Philippos'un babası, Augustuslar'in procurator' $\mathbf{u}$, kendi agonothetes' $\mathrm{i}$, logistes'i ve euergetes'i Gaius Iulius Philippos'u onurlandırmaktadırlar. Heykelin dikim işiyle Tiberius Claudius Sperkheios ve Serapion oğlu, Magnesia ad Sipylum kentli, olympionikes Serapion ilgilenmiştir." Karş. Sargın 2017, 155, T1-11b.

${ }_{25}$ Antik Dönem'de Lydia'daki sosyal ve ekonomik açıdan değerlendirilen derneklere ilişkin daha ayrıntılı bilgi için bkz. Tanrıver 1996. Ayrıca Smyrnalılar'ın synodosu için bkz. a.g.e., 51-52.

${ }_{26}$ Pergamonlu bir başka heykeltraşın ismi Aigai'da bouleuterion'da ele geçen iki heykelden öğrenilmektedir. Heykelin alt kısmında heykeli "Pergamonlu Hippias oğlu Menestratos'un yaptırdığı" ifade edilmiştir. Bkz. Sezgin \& Aybek 2015, 32-34.

${ }^{27}$ Heykeltraşlar gezici olarak işlerini yürütebilirlerdi, hatta sipariş üzerine Roma'ya giderek mesleğini icra eden Aphrodisias'll heykeltraşlar bilinmektedir. Bkz. Erim - Reynolds 1991, 517-538.
} 
Az sayıda ele geçen mezar yazıtı arasından bazılarının sonunda para cezası ile formüle edildiği tespit edilmiştir. Buna göre mezar sahibi kendi mezarına; yazıtta bizzat yazdırdığı isimlerin dışında başka hiç kimsenin gömülmeye izinli olmadığını belirtmiştir. Bu örneklerden bazılarında mezarı açmaya cesaret edenlerin 500 denaria imparator kasasına (fiscus); 1500 denaria kent kasasına ve yine 500 denaria Meter Theon Sipylene'ye ödemek zorunda olduğunu göstermektedir.

Epigrafik belgelerde geçen şahıs isimlerinin ağırlıklı olarak Hellence olmak üzere epikhorik ve Latince isimler olduğu belgelenmektedir. Bunlar arasından Athenaios, Apollas, Apolloniketes, Apollonios, Artemidoros, Asklapis, Asklepides, Dionysios, Diognetos, Diodotos, Diokles, Dionytas, Theaitetos, Hermagoras, Hermeias, Hermogenes, Metrodora, Metrodoros, Mithres ve Serapion tanrı ya da tanrıçaların isimlerinden türetilmiş theophorik kökenli isimlerdir. Ayrıca yazıtlardan femininum ve masculinum cinsinde yerel isimlerin de olduğu öğrenilmektedir. Örneğin, Gemnis ismi Lydia Bölgesi'nde sadece Magnesia ad Sipylum'da belgelenmiştir (LGPN VA, 108).

\section{Kentin Dinsel Yapısı}

Dağ Tanrıçası olarak bilinen Meter Oreia ${ }^{28}$ Anadolu'da özel bir dağı simgeleyen veya onun kutsal alanı olan isimlerle tapınım görmüştür (Akın 2016, 147-151). Nitekim Meter Oreia'ya Magnesia ad Sipylum'da, Meter Sipylene ya da Meter Plastene epithetonları ile rastlanmaktadır. Batı Anadolu'da "Sipylene" epithetonu Sipylos Dağı'dan gelmektedir. Söz konusu yazıtta adı muhtemelen Pamph[ylios?] olan biri adak heykelini altlığ1 (basis) ile birlikte Tanrıça Meter Sipylene'ye ve halka adamaktadır (Buresch 1898, 138; I. v. Magnesia, no. 16; TAM V.2 1357; Paz de Hoz 1999, no. 40.99). Kentten bilinen bir diğer Meter Sipylene adağı Aurelius Tryphon isimli birinin mezar yazıtından öğrenilmektedir (I. Magnesia ad Sipylum, no. 24; TAM V.2 1375). Yazıtta Aurelius Tryphon, kendisi ve bütün ailesi için yaptırmış olduğu heroona kendilerinden başka hiç kimsenin gömülmeye izinli olmadığını

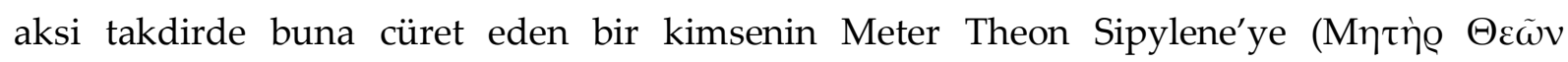
$\Sigma\llcorner\tau v \lambda \eta v \eta ́) ~ 500$ denaria ödeyeceğini belirtmektedir. Burada Meter Sipylene'ye ek olarak Ana Tanrıça'nın (Meter) yazıtlarda sıklıkla karşılaşılan Theon ( $\Theta \varepsilon \tilde{\omega} v)$ epithetonu da eklenmiştir. Strabon (10.3.12), Sipylos Dağı üzerinde Meter Sipylene'nin bir kült alanının olduğunu ve Tanrıça'ya Phrygialılar'ın da tapındığını aktarmaktadır. Magnesia ad Sipylum ile Smyrna arasında yapılan sympoliteia anlaşma yazıtında Meter Sipylene'nin adı geçmektedir (I. $v$. Magnesia, no. 1, str. 61 ve 70 = I. Smyrna II.1, no. 573). Bu anlaşma metnine göre Tanrıçanın her iki kentte de tapınım görmüş olduğu anlaşılmaktadır. Ayrıca Tanrıça, Smyrna' da "Meter

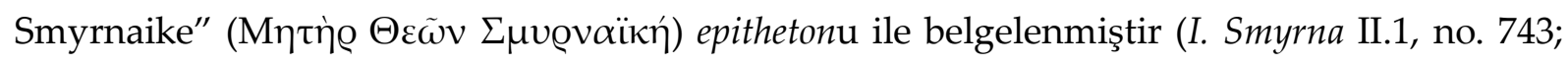
Vermaseren 1987, no. 547).

${ }_{28}{ }^{\prime D}$ Dağ Ana(s1)” veya "Dağlarda Oturan Tanrıça” anlamlarına gelen Meter Oreia, Anadolu'nun çeşitli yerlerinde Ana Tanrıça olarak kabul edilen Meter (Kybele) isminin yanına eklenen epithetonlardan biridir. Meter Oreia ile ilgili daha ayrıntılı bilgi için bkz. Akın 2016, s. 143-188. 
Magnesia ad Sipylum'dan bilinen bir diğer Tanrıça yukarıda değindiğimiz gibi Meter Sipylene' nin diğer epithetonu Meter Plastene'dir. Kentten ele geçen bir yazıta göre (Contoléon 1887, (BCH 11), s. 300, no. 8; I. v. Magnesia, no. 37; TAM V.2 1354) Apollas kızı Metrodora adında birisi Meter Plastene'ye altlı̆g ile birlikte bir heykelcik adamıştır. Meter Plastene'ye ait bir diğer yazıttan ise Orpheus'in, Meter Theon Plastene'ye adak adadığı öğrenilmektedir (I. Magnesia ad Sipylum, no. 38; TAM V.2 1353). Meter Plastene'nin belgelendiği bir başka yazıt ise Apollonios Skytalas'ın onurlandirılma kararıdır (I. v. Magnesia, no. 36; TAM V.2 1352). Yazitta demos ve boule, kendi memleketi için ünsever ve yüce gönüllü bir şekilde her şeyi sağlayan Apollonios Skytalas'ı onurlandırmaktadırlar. Zira Skytalas, Tanrıça Meter Plastene'ye temelinden itibaren bütün süslemesiyle birlikte ve masraflarını kendi parasıyla karşıladığı bir tapınak adamıştır. Bununla birlikte Pausanias (V 13,4), Sipylos Dağı üzerinde Meter Plastene' nin kutsal alanının olduğundan bahsetmektedir.

Kentten bilinen bir diğer adak yazıtı (I. v. Magnesia, no. 15; TAM V.2 1348), Menippos oğlu adı bilinmeyen biri tarafından Mısır Tanrıları Sarapis ve İsis için yazılmıştır. Yazıtta tanrılar için hizmet eden görevlilerin isimleri de liste halinde bulunmaktadır.

Apollonios adında birisinin küçük bir adak heykelciğini Semele için adadı̆̆ı İs. 1. - 2. yüzyıllara tarihlenen bir yazıttan öğrenilmektedir (Keil - Premerstein 1908, no. 1; I. $v$. Magnesia, no. 17).

Kentten ele geçen bir başka yazıttan (I. v. Magnesia, no. 31; TAM V.2 1412) Tiberius Claudius Sextus'un Hormoitenoi katoikiasında, Zeus'a kaidesi (basis) ile birlikte bir heykel adadığı öğrenilmektedir.

Kentin dinsel yapısındaki çeşitliliğe işaret eden birisi ise Yahudi Straton'un kent yaşamındaki varlığıdır. Kentten ele geçen bir mezar yazıtında “Tyrannos oğlu Iudaialı Straton, henüz hayattayken bu mezarı kendisi, karısı ve çocukları için yaptırdı" (IGRR IV, 1743; I. v. Magnesia, no. 27) ifadeleri yer almaktadır.

Sonuç olarak, yazıtlar ve antik edebi eserler doğrultusunda Magnesia ad Sipylum Kentinin tarihi, coğrafik konumu ve sosyal-kültürel yaşamına ilişkin bilgiler elde edilebilmiştir. Kent, kendisine ait polis niteliğindeki kararları demos ve boule gibi idari kurumlarla almaktadır. Demos ve boule dışında, kentin yönetim sisteminde strategoslar bazı önemli kararların alınması için bir dilekçe ya da öneride bulunarak yetki sahibi olmuşlardır.

Hellenistik Dönem'de Lysimakhos ve Seleukos I ile Kourupedion ve Antiokhos III ile Romalılar arasında Magnesia gibi önemli savaşların meydana gelmesi kentin üne kavuşmasını sağlamıştır. Bu savaşların sonucunda Magnesia ad Sipylum'un her zaman Roma'nın yanında yer aldığı görülmektedir.

Roma Dönemi'ne gelindiğinde Magnesia ad Sipylum'un Roma'nın yine müttefik ve dostu olduğunu göstermiştir. Pontos Kralı Mithradates VI Eupator ile yapılan savaşta Romalılar'a verdikleri desteklerinden dolayı Sulla tarafından özgür kent (civitas libera) statüsüyle ödüllendirilmişlerdir. Kent ile ilgili mahkeme konuları provincia Asia'ya bağlı Smyrna conventus'una dahil edilmiştir. Bunların dışında kentin gündelik yaşamındaki sosyal ve kültürel faaliyetler, epigrafik belgelerin aktardığı kadarıyla tespit edilebilmektedir. 


\section{Kisaltmalar}

AST: Araştırma Sonuçları Toplantısı.

$B C H$ : Bulletin de correspondance hellénique.

CIG: Corpus inscriptionum graecarum, Berlin 1828-1877.

CIL: Corpus Inscriptionum Latinarum, Berlin 1863 vdd.

DNP: Der Neue Pauly, Enzyklopadie der Antike.

IG: Inscriptiones Graecae, Berlin 1877 -.

IGRR: Inscriptiones Graecae ad Res Romanas Pertinentes.

IK: Inschriften griechischer Stadte aus Kleinasien.

ILS: H. Dessau, Inscriptiones latinae selectae, Berlin 1892-1916.

LSJ: Liddell, H. G. \& R. Scott, (1996). A Greek-English Lexicon, with a Revised Supplement, Oxford.

OGIS: Dittenberger, W. (1903-1905). Orientis Graeci Inscriptiones Selectae, Leipzig.

PIR: Prosopographia Imperii Romani.

$R E$ : G. Wissowa et al., Realencyclopädie der classichen Altertumwissenschaft

(Stuttgart - München 1893-1980).

TAM V.2: P. Herrmann (1989). Tituli Asiae Minoris V. Tituli Lydiae linguis Graeca et Latina conscripti. Fasc. II: Regio sept aus dem rauhen Kilikien entrionalis ad occidentem vergens, Viyana.

\section{Kaynakça}

Akın, Y. (2016). Küçük Asya'da Dağ ve Mağara Tanrıları. Meter Oreia Kültü ve İlgili Yazıtlar. Şurada: N. Eda Akyürek Şahin et alii (eds.), Eskiçağ Yazıları 8, [Akron 10], (Akdeniz Dilleri ve Kültürlerini Araştırma Merkezi Yayını), İstanbul, 143-203.

Akşit, O. (1983). Manisa Tarihi (Magnesia ad Sipylum) (Başlangıcından M.S. 395 Yılına Kadar), İstanbul.

Akurgal, E. (1989). Anadolu Uygarlıkları, İstanbul.

Arslan, M. (2007). Roma'nın Büyük Düşmanı Mithradates VI Eupator, İstanbul.

Bean, G. B. (1997). Eskiçağda Ege Bölgesi, İstanbul.

Bossert, H. T. (1942). Anatolien, Berlin.

Buresch, K. (1898). Aus Lydien. Epigraphisch-geographische Reisefruchte, Leipzig.

Cohen, G. M. (1995). The Hellenistic settlements in Europe, in islands and Asia Minor, Oxford.

Contoléon, A. (1887). "Epigraphai anekdotoi", Bulletin de Correspondance Hellénique 11, 296-301.

Corsten, Th., Catling, R. W. V. \& Ricl, M. (2010). A Lexicon of Greek Personal Names V A (=LGPN V): Coastal Asia Minor: Pontos to Ionia, Oxford.

Çă̆, Ç. (2017). “Bir Kent Memuru Olarak Stratēgia: Anadolu Kentlerinde Hellenistik Dönem Strategos'ları", Phaselis III, 281-295.

Çağ, Ç. (2018). Roma İmparatorluk Dönemi Küçük Asya'sında Bir Kent Memuriyeti Olarak Strategōs'luk (Akdeniz Üniversitesi, Sosyal Bilimler Enstitüsü, Eskiçă̆ Dilleri ve Kültürleri Ana Bilim Dalı, Yayımlanmamış Doktora Tezi), Antalya. 
Çokbankir, N. (2010). Yazıtlar Işı̆̆ında Roma İmparatorluk Çağı Küçük Asya Agonları ve Sporcuları (Akdeniz Üniversitesi, Sosyal Bilimler Enstitüsü, Eskiçağ Dilleri ve Kültürleri Ana Bilim Dalı, Yayımlanmamış Doktora Tezi), Antalya.

Daubner, F. (2013). Magnesia ad Sipylum, R. S. Bagnall - K. Brodersen - C. B. Champion - A. Erskine \& S. R. Hubner (eds.), The Encyclopedia of Ancient History, First Edition, Oxford, basilı sayfa 4235 .

Doğan, M. U. (2007a). Magnesia Ad Sipylum Arkeoloji, Topografya ve Tarihi Coğrafya İncelemesi (Dokuz Eylül Üniversitesi, Sosyal Bilimler Enstitüsü, Yayımlanmamış Yüksek Lisans Tezi), İzmir.

Doğan, M. U. (2007b). “Manisa İl Merkezinde Keşfedilen Polygonal Duvarların Sipylos Magnesiası'nın Erken Dönemi ile İlişkisi”, Türk Arkeoloji ve Etnografya Dergisi 8, 79-90.

Doğan, M. U. (2008a). “Spil (Manisa) Dağı'nın Kuzey Yüzündeki Bir Grup Kaya Anıtı”, Türk Arkeoloji ve Etnografya Dergisi 8, 69-78.

Doğan, M. U. (2008b). “Sipylos Magnesiası Arkeolojisine Işık Tutan Yeni Bulunmuş Bir Kabartma", Türk Arkeoloji ve Etnografya Dergisi 8, 125-132.

Eilers, C. (1999). "M. Silanus, Stratoniceia, and the Governors of Asia under Augustus", Tyche 14, 77-86.

Engelmann, H. (1976). Die Inschriften von Kyme, (I. v. Kyme = IK 5), Bonn.

Engelmann, H. - Knibbe, D. - Merkelbach, R. (1980). Die Inschriften von Ephesos, Teil III (I. v. Ephesos III = IK 13), Bonn.

Erhat, A. (1989). Mitoloji Sözlüğü, İstanbul.

Erim, K. T. \& Reynolds, J. J. M. (1989 [1991]). Sculptors of Aphrodisias in the inscriptions of the city, Festschrift J. İnan, İstanbul, 517-538.

Ermiş, Ü. M., Gündüz Küskü, S. \& Yılmaz, A. (2016). “Erken Demirçağ’ından Ortaçağ’a Manisa Kalesi", Tüba-Ked 14, 247-259.

Gökalp Özdil, N. (2018). "Yazıtlar Işığında Küçükasya'da Stephanephoria”, History Studies International Journal of History 10 (3), 197-205.

Grainger, J. D. (2002). The Roman war of Antiochos the Great: 307-327, Leiden.

Greenewalt, C. H. Jr. (2010). Giriş. şurada: Lidyalılar ve Dünyaları, Cahill, N. D. (ed.), İstanbul, 7-36.

Ihnken, T. (1978). Die Inschriften von Magnesia am Sipylos (I. v. Magnesia = IK 8): Mit einem Kommentar zum Sympolitievertrag mit Smyrna, Bonn.

Keil, J. \& Premerstein, von A. (1908). Bericht über eine Reise in Lydien und der südlichen Aiolis: 1-5, Viyana.

Laum, B. (1914). Stiftungen in der griechischen und römischen Antike, Ein Beitrag zur Antiken Kulturgeschichte, Band II, Leipzig, Berlin.

le Bas, P. - Waddigton, W. H. (1972). Inscriptions grecques et latines recueillies en Grece et en Asie Mineure, Paris (1847-1877).

Magie, D. (1950). Roman Rule in Asia Minor to the End of the Third Century After Christ I-II, Princeton, New Jersey. 
Malay, H. (1983). "Batı Anadolu'nun Antik Çağdaki Ekonomik Durumu”, Ege Üniversitesi Arkeoloji ve Sanat Tarihi Dergisi 2, 50-61.

Malay, H. (1984). “Manisa ve Denizli İllerinde Epigrafi Araştırmaları”, AST II, 99-101.

Malay, H. (1994). Greek and Latin Inscriptions in the Manisa Museum, (ETAM 19), Viyana.

Meriç, R. (1986). “1984 Yılı İzmir ve ‘Manisa İlleri Yüzey Araştırmaları”, AST III, 199-209.

Meriç, R. (1987). “1985 yılı İzmir ve Manisa İlleri Yüzey Araştırmaları”, AST IV, 301-311.

Meriç, R. (1988). “1986 yılı İzmir ve Manisa İlleri Yüzey Araştırmaları”, AST V/1, 247-257.

Meriç, R. (1989). “1987 yılı İzmir ve Manisa İlleri Yüzey Araştırmaları”, AST VI, 385-393.

Meriç, R. (1990). “1988 Yılı İzmir, Manisa İlleri Arkeolojik Yüzey Araştırması”, AST VII, 361366.

Paz de Hoz, M. (1999). Die lydischen Kulte im Lichte der griechischen Inscriften (AMS 36), Bonn.

Petzl, G. (1987). Die Inschriften von Smyrna II,1 (I. Smyrna II.1 = IK. 24,1), Bonn.

Poljakov, F. B. (1989). Die Inschriften von Tralleis und Nysa (I. v. Tralleis - Nysa I = IK 36.1), Bonn.

Robert, J. \& Robert, J. (1948). Hellenica VI, 127-131.

Sargın, Y. (2017). Roma İmparatorluk Dönemi Küçük Asya'sında curatores rei publicae (Akdeniz Üniversitesi, Sosyal Bilimler Enstitüsü, Eskiçağ Dilleri ve Kültürleri Ana Bilim Dalı, Yayımlanmamış Doktora Tezi), Antalya.

Sargin, Y. (2019). Lidya-Likya (Ansiklopedi maddeleri), Turizm Ansiklopedisi - Türkiye: Turizm ve Ağırlama Endüstrisinin Temel Kavramları, 25-27.

Sezgin, Y. \& Aybek, S. (2015). A Group of Portrait Statues from the Bouleuterion of Aigai: A Preliminary Report, şurada: Eikones Portraits en Contexte Recherches nouvelles sur les portraits grecs, Hoff, von R., Queyrel F. \& Perrin-Saminadayar E., Paris, 17-43.

Şahin, I. (1998). Lydia'da Küçük Yerleşimler, (Ege Üniversitesi, Yayımlanmamış Doktora Tezi), İzmir.

Tanrıver, C. (1996). Antik Devirde Lydia'da Sosyal ve Ekonomik Amaçlı Dernekler (Ege Üniversitesi, Yayımlanmamış Doktora Tezi), İzmir.

Tanrıver, C. (2006). Antik Devirde Hermos (Gediz) Vadisinde Şehirleşme, Geçmişten Geleceğe Köprü: Yanık Ülke Kula Sempozyumu (Bildiriler),1-3 Eylül 2006, İzmir.

Umar, B. (2001). Lydia, İstanbul.

Vermaseren, M. J. (1987). Corpus Cultus Cybelae Attidisque (CCCA) I: Asia Minor, Leiden. Weisser, B. (2008). Die Basis von Pozzuoli, Antike Plastik 30, Bordbein, A. H. (ed.), München, 105-160, Taf. 48-67. 